\title{
Charting service quality gaps
}

\author{
CARLOS J. F. CÂNDIDO ${ }^{1} \&$ D. S. MORRIS ${ }^{2}$ \\ ${ }^{1}$ UCEE, Universidade do Algarve, Campus de Gambelas, 8000 Faro, Portugal. \\ ${ }^{2}$ Sheffield Business School, Sheffield Hallam University, Sheffield S1 1WB, UK.
}

\section{Introduction}

Some of the most influential models in the service management literature (Parasuraman et al., 1985; Grönroos, 1990) focus on the concept of service quality gap (SQG). Parasuraman et al. (1985) define a pioneering model with five SQGs, the concepts of which are amplified in Brogowicz et al.'s (1990) model. The latter has five types of encompassing gaps: information and feedback-related gaps; design-related gaps; implementation-related gaps; communication-related gaps; and customers' perceptions and expectations related gaps. Additionally to this model amplification, other authors (e.g., Brown \& Swartz, 1989) have pointed to relevant SQGs that have not been considered previously.

This paper integrates current models and a group of SQGs dispersed through the literature in a new comprehensive model. It draws a link between the model and the stages of a strategy process, emphasising the SQGs' impact on the process and raising relevant research questions.

\section{An enlarged set of SQGs}

Several references to possible service quality inconsistencies, some of which explicitly formalised as SQGs, were collected from the literature and are listed in the rows of Table 1 . The sources from where they were drawn are listed in the columns' headings, and indicated by a dot “ $\bullet$ " in the body of the table. 
Table 1. Quality inconsistencies/gaps drawn from the literature

\begin{tabular}{|c|c|c|c|c|c|c|c|c|c|c|}
\hline $\begin{array}{l}\bar{\Xi} \\
\text { है } \\
\text { है } \\
\text { है }\end{array}$ & Inconsistency /gap & 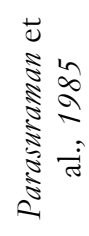 & 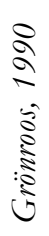 & 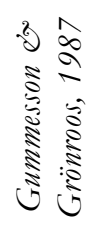 & 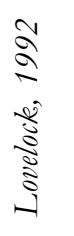 & 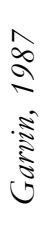 & 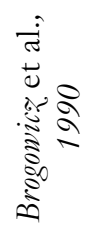 & 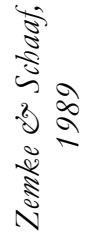 & 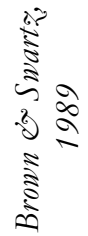 & 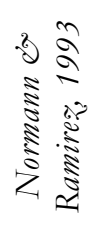 \\
\hline 1 & Management perceptions & - & $\bullet$ & & $0^{a}$ & - & - & - & & \\
\hline 2 & Service quality strategy & & 0 & & & $\bullet$ & & - & & \\
\hline 3 & $\begin{array}{l}\text { Service design and service quality } \\
\text { specifications in terms of customers' } \\
\text { expectations }\end{array}$ & - & - & - & $0^{a}$ & - & - & - & & \\
\hline 4 & Quality supportive financial function & & & & - & & & & & \\
\hline 5 & Internal communications & & - & - & & & & - & & \\
\hline 6 & Integration/coordination & - & - & - & - & & & & & \\
\hline 7 & $\begin{array}{l}\text { Coordination of other people and/or } \\
\text { organizations in the value system }\end{array}$ & & & & & & & & & - \\
\hline 8 & $\begin{array}{l}\text { Selection, training, and adequate } \\
\text { levels of autonomy, power and } \\
\text { rewards to personnel }\end{array}$ & & - & & - & & & - & & \\
\hline 9 & Service delivery & $\bullet$ & $\bullet$ & - & $e^{a}$ & - & - & - & & \\
\hline 10 & External communications & - & - & & - & & • & & & \\
\hline 11 & $\begin{array}{l}\text { Contact personnel's perceptions of } \\
\text { customers' expectations }\end{array}$ & $\square$ & $\square$ & $\square$ & 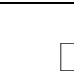 & $\square$ & $\square$ & $\square$ & - & \\
\hline 12 & $\begin{array}{l}\text { Contact personnel's perceptions of } \\
\text { customers' experiences }\end{array}$ & $\square$ & $\square$ & $\square$ & 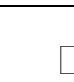 & $\square$ & $\square$ & $\square$ & • & \\
\hline 13 & Consumer perceptions & - & - & - & & & - & & - & \\
\hline 14 & Service quality evaluation & & - & & - & - & & - & & \\
\hline
\end{tabular}

Note: a Although Lovelock (1992) does not specifically identify each of these gaps, he refers to a possible inconsistency between the consumers' preferences and the nature of the delivery system.

The inconsistencies listed are considered relevant SQGs on their own and the resulting group of 14 SQGs is reordered and renumbered in a logical sequence, as shown in the table.

These SQGs are defined and coherently integrated, below, as part of a new SQG model. Before that, other elements of the model must be shortly introduced.

\section{Elements of the model}

A management model should identify and relate those key elements that require systematic management attention (Brogowicz et al., 1990). The elements proposed to fit in the model are: 
- management's perceptions of customer expectations and perceptions about the service;

- vision, mission, service strategy and directions to eliminate the gaps;

- service analysis, translation of perceptions into service quality specifications and service design;

- financial and human resources (HR) management;

- external communication; and

- service delivery system (production, delivery and "part-time" marketing).

Figure 1 shows the elements and some fundamental relationships between them, namely:

- management's perceptions influence on mission, strategy and directions to eliminate gaps;

- mission and strategy's influence on HR management, financial management, service specifications and design, external communications, and delivery system;

- external communications influence on consumer expectations and perceptions; and the

- relationships between specifications, finance, HR management and the service delivery system. 
Figure 1. Service quality gap model: basic elements and some fundamental relationships

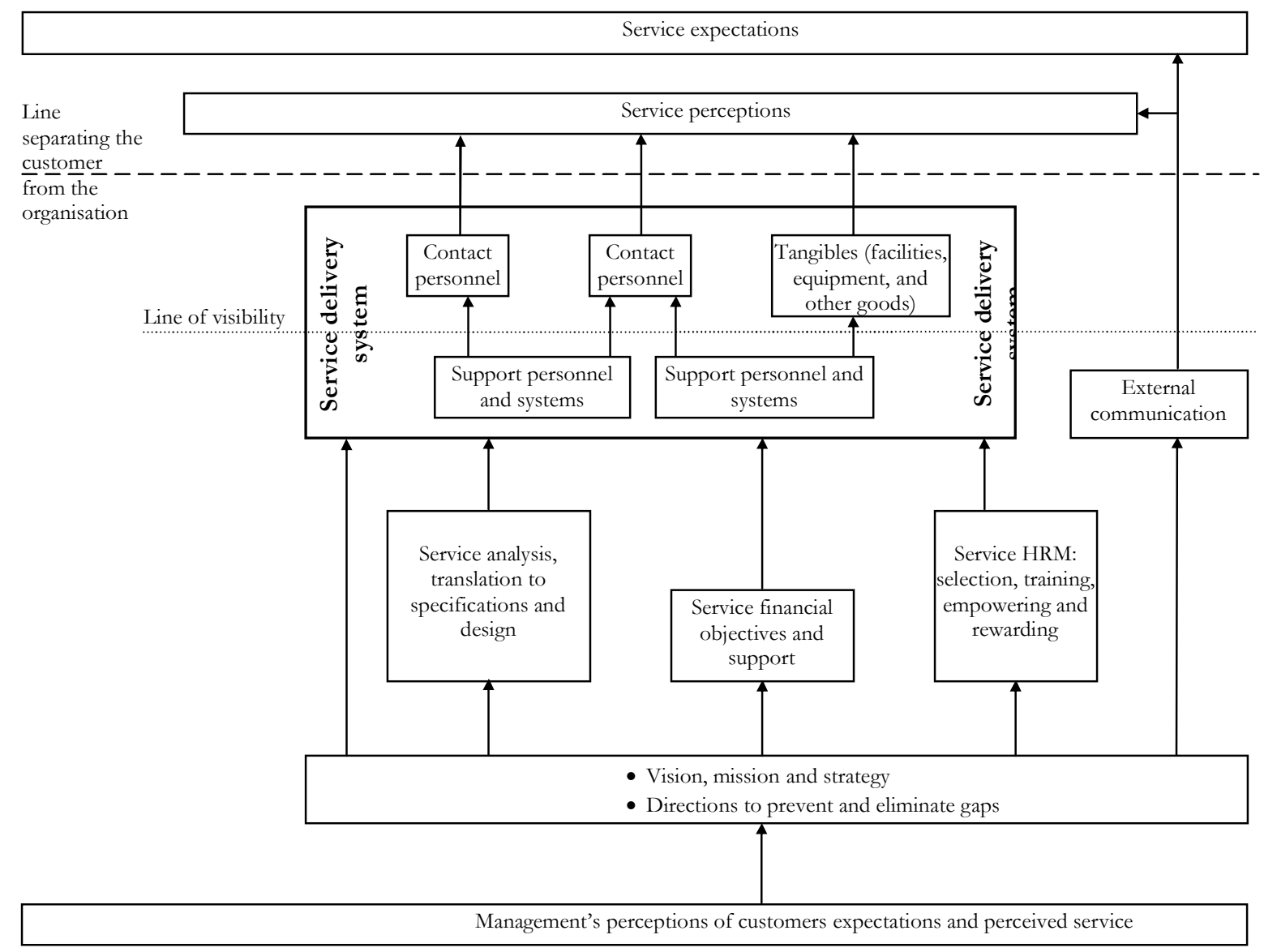

Figure 1 also shows the basic elements of a service delivery system - tangibles, support systems, support personnel and contact personnel - and their connections. The elements of a service delivery system that are in contact with consumers are depicted above the line of visibility, while support personnel and systems are shown below that line. Finally, among the elements that influence the customer's expectations, only external communication is shown to avoid excessively burdening the figure.

The elements of the model and the relationships established are drawn or synthesised from Shostack (1984), Parasuraman et al. (1985), Adams \& Colebourne (1989), Brown \& Swartz (1989), Rosander (1989), Brogowicz et al. (1990), Grönroos (1990), Gummesson (1990), Lovelock (1992), Christopher et al. (1993), Irons, (1994), Bateson (1995) and Normann (1995). 


\section{A synthesised SQG model}

The SQG model proposed here integrates contributions from the above and other studies.

Figure 2 shows the model, incorporating the elements already mentioned and the 14 SQGs identified. Definitions for the SQGs are outlined in this section.

Figure 2. Service quality gap model

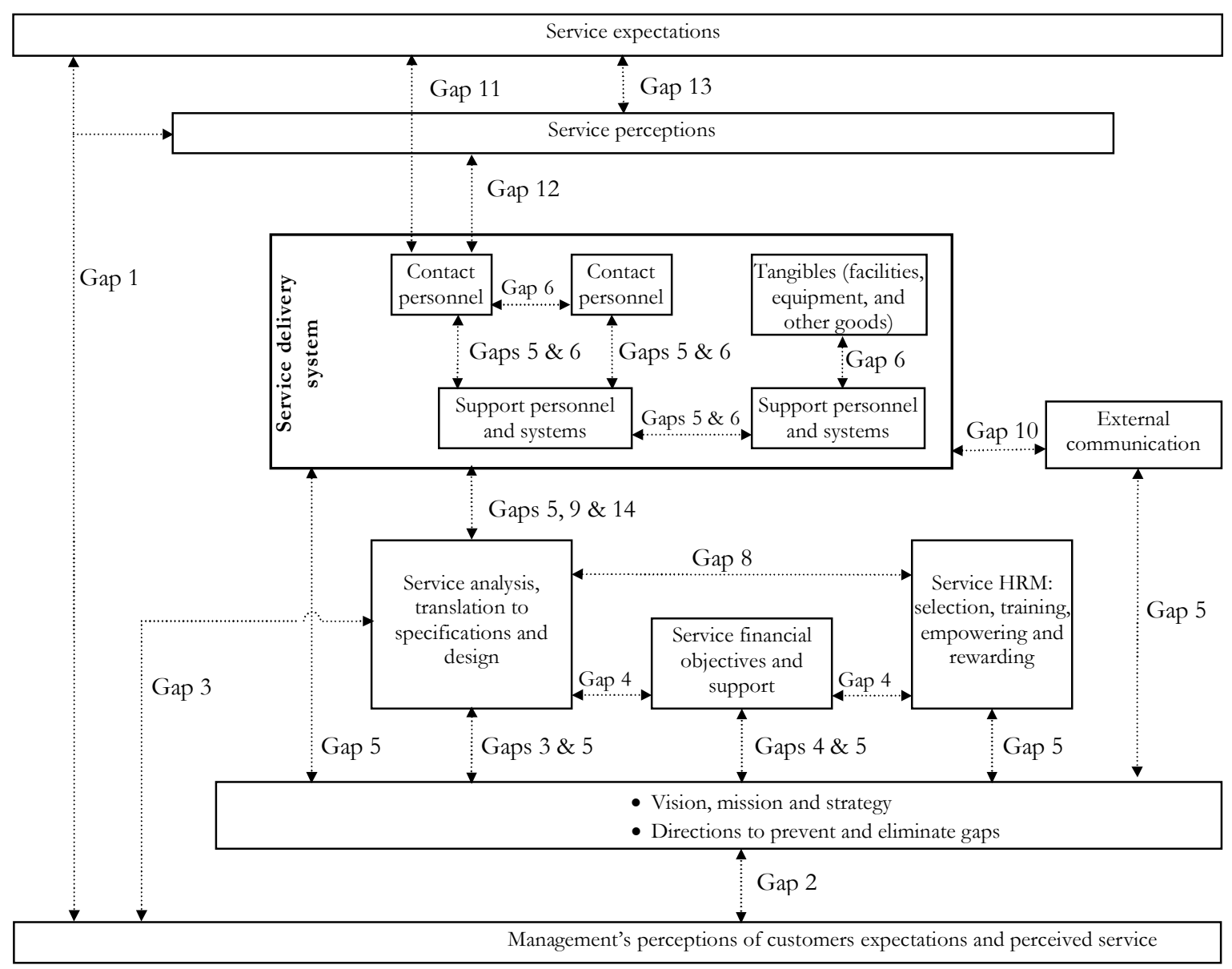

Note: Gap 7 can occur between organisational elements and stakeholders. It is not represented for a simplification reason.

Gap 1 - management perceptions. Zemke \& Schaaf (1989) note that «left to [their] own devices, [managers and personnel] pay more and more attention to things of less and less importance to the customer». As a consequence, they remain blind to what customers actually value. Some of the "devices" and causes for this blindness are managers and personnel's education, habits developed over time, company policies and procedures, especially relating to marketing research and communication (Zemke \& Schaaf, 1989; Zeithaml et al., 1988). 
Gap 1 is defined here as a management lack of understanding of customers expectations and perceptions of the service, motivated by both lack of initiatives to listen to customers (Zemke \& Schaaf, 1989) and by a lack of correct understanding when these initiatives are taken (Parasuraman et al., 1985). The gap can be further enlarged to include a lack of understanding of other external information.

Gap 2 - service quality strategy. Strategy relates the service organisation to its environment and defines the way it wants to compete. Service quality strategy precises the organisation's competitive scope and its concept of quality, through a selection of, and positioning on, the fundamental quality dimensions it wants to compete with (e.g., tangibles and empathy).

Quality dimensions are correlated (Parasuraman et al. 1988 \& 1991) and, sometimes, an improvement in one may be achieved only at the expense of another (Garvin, 1987). The challenge is to choose a balanced combination and positioning (Garvin, 1987; HaywoodFarmer, 1988). Highly concentrating on some dimensions may also constitute an appropriate strategy, but may lead to disaster (Haywood-Farmer, 1988).

Finally, service quality strategy is a set of guidelines that provides orientation for everyone in the organisation. It should be thoroughly communicated, should be meaningful for personnel, and should distinguish the organisation from others. Failure to forge and communicate a coherent service quality strategy is a serious SQG.

Gap 3 - service design and service quality specifications in terms of customers' expectations. Specifications, along the strategic quality dimensions, are useful to define what quality is. Frequently, organizations do not possess any kind of formal specifications, which results in aggravated service variability and lower quality (Zemke \& Schaaf, 1989). Specifications are required to guide personnel in their activities. Specifications are also required as a means of comparison for effective quality evaluation. Setting adequate specifications does not mean total standardisation, but requires an analysis and design of the total service, i.e., of every moment of truth. From these ideas, Gap 3 is defined as: 
- a lack of analysis, design and definition of service quality specifications, or when specifications exist, as

- an inconsistency between those specifications and the strategy content or the perceptions management held of customers' expectations.

Several factors can originate this gap, for instance, lack of management commitment to service quality and short-term profit orientation (Zeithaml et al., 1988).

Gap 4 - quality supportive financial function. Although a vital function to the service organisation, finance involves little customer contact, except for billing, payment and credit activities (Lovelock, 1992). This is one reason why it has been neglected in the service literature. Financial management, in service organisations, has also been seen mainly as a constraint and an obstacle to other functions (Adams \& Colebourne, 1989).

Adams \& Colebourne (1989) suggest an "enlightened" approach to finance in service organisations. This consists of a more participative and positive approach where far from being an obstacle, it contributes to strategic planning, costing systems, personnel motivation, quality control, continued solvency, and keeping outsiders' confidence in management (Adams \& Colebourne, 1989).

Particularly, there is a need to distinguish "good costs", that improve organisational capabilities, from "bad costs", that increase bureaucracy (Grönroos, 1990). Doing this will, probably, require a substantial effort, understanding, cooperation and good will from financial managers and personnel to avoid traditional methods and arguments.

Gap 5 - internal communications. Zemke \& Schaaf (1989) insist that service strategy has to be communicated over and over again to everyone in the organisation; the «employees at all levels must be aligned with a single vision of what the organisation is trying to accomplish». Effective internal communications is the requisite for integration and harmony in the service organisation's activities and quality. Internal communications is not only about strategy, it has to 
do with managers listening to employees, receiving feedback about the employee's perceptions of the organisation's performance on its fundamental quality dimensions. It also involves managers working with and listening to other managers, thus sharing problems and solutions; managers giving information to employees, about their individual performances, thus contributing to individual improvement; and involves prompt horizontal and both ways vertical communications, thus flattening and inverting the hierarchical pyramid (Grönroos, 1990; Irons, 1994).

Gap 6 - integration/coordination. Integration between every employee, every activity, every department and every function is fundamental for service quality strategy's success. The need for integration efforts arises from the differentiation of jobs and functions in the organisation. This differentiation implies differences in cost/revenue orientations, policies and in specific external environments, which can easily lead to misunderstandings, lack of coordination and even conflict (Lawrence \& Lorsch, 1967; Lovelock, 1992). Integration can be achieved through several distinct devices, for instance, promoting employees mobility inside the organisation, cross training, task forces, team projects, supervision and, basically, good internal communications (Cf. Lawrence \& Lorsch, 1967; Mintzberg, 1979; Lovelock, 1992). There are two sides to integration. One is that every job, activity, department and function should be compatible and mutually reinforcing (Normann, 1995; Lovelock, 1992). The other is that customers must never feel ignored, unimportant or abandoned, e.g., repeatedly sent from one department to another (Grönroos, 1990; Lovelock, 1992).

Gap 7 - coordination of other people and/or organisations in the value system. External coordination is also fundamental. If the external organisations in the value system are not organised to provide service quality to the final consumer, this lack of understanding and coordination can result in poorer customer's perceptions. Normann \& Ramirez (1993) report that several organisations have achieved a total reconfiguration of the value constellation to which they belong, with benefits to every member of the network and consumers. Thus, Norman (1995) 
suggests that service firms «have to extend their organising capability well outside their own company»; that they have to "organise" its client; and that they can benefit from doing the same even with «groups or sectors normally regarded as separate».

Gap 8 - selection, training, and adequate levels of autonomy, power and rewards to personnel. The importance of functional quality in service industries makes HR management highly important. HR management involves selection, training, giving adequate levels of autonomy, setting standards/objectives, accessing individual performance, helping people where help is needed and, finally, rewarding them for their achievements. The right people should be selected and the tendency to recruit quickly, accepting candidates with inadequate attitudes, values and skills, should be avoided (Zemke \& Schaaf, 1989). Selected people are trained to enhance skills, improve attitudes towards customers and learn about the services offered. These people can be slowly vested with substantial responsibility, enabling them to solve customer problems in a more autonomous and satisfactory way to both parties (Zemke \& Schaaf, 1989; Irons, 1994). Contact personnel are encouraged to feedback information about customers' expectations and perceptions. Finally, personnel are rewarded for excellent service quality and their achievement is made public (Zemke \& Schaaf, 1989). Inability or unwillingness to coherently manage personnel constitutes a significant SQG.

Gap9- service delivery - is an inconsistency between service design/service quality specifications and the service quality actually delivered by the service delivery system. The inconsistency may be technical quality and/or process quality related. It can be analysed more precisely using the strategic quality dimensions selected. This means that on each of these dimensions can be found a SQG. Thus, gaps 9.1 to $9 . \mathrm{N}$ can now be defined, $\mathrm{N}$ being the number of strategic quality dimensions. Gap 9.1, for example, might be a difference between the designed level of reliability and the level of reliability actually delivered by the system. ${ }^{1}$ Gap 9

\footnotetext{
${ }^{1}$ See Brogowicz et al.'s (1990) disaggregation of Parasuraman et al.'s (1985) Gap 5.
} 
can, consequently, be defined as a function of gaps 9.1 to 9.N. Such gaps result from employees' inability or unwillingness to perform (Zeithaml et al., 1988).

Gap 10 - external communications - is an inconsistency between what is externally communicated (promised) and what the service delivery system is actually able to provide the customers with. Several factors may be in the origin of the gap: a lack of communication between the marketing department's members and the operations department's members, a propensity to overpromise (Zeithaml et al., 1988), or an inability to communicate clearly and accurately the benefits of the service offering to the customers (Brogowicz et al., 1990).

In order to adequately use and fully appreciate the choices that the organisation offers, the customer has to be in possession of accurate and comprehensive information. It may be necessary to use more than one communication means to inform, persuade and educate the customer. Designing services to be user friendly will simultaneously facilitate consumer use and external communication.

Gap 11 - contact personnel's perceptions of customers' expectations. This gap consists of a discrepancy between the contact personnel's perceptions of customers' expectations and the customers' real expectations (Brown \& Swartz, 1989).

Gap 12 - contact personnel's perceptions of customers' experiences. Similar to the previous gap, Gap 12 consists of a discrepancy between the contact personnel's perceptions of customers' experiences and the customers' real experiences (Brown \& Swartz, 1989).

These gaps can have most impact in professional services, where «professionals' perceptions most directly affect the design and delivery of the services offered» (Brown \& Swartz, 1989). But, even in other services, these gaps can have a significant impact, because they address the need of contact employees to understand a customer's expectations and experiences. Specifically, when Gap 11 is nil, the employee will have evaluated correctly the customer's expectations, and when Gap 12 is nil, his perceptions. In conjunction, these two 
gaps will affect the contact employee's perceptions of his interlocutor's assessment of the quality he is being provided with and the employee's subsequent behaviour.

Gap 13 - consumer perceptions - is the difference between what consumers expect from the service and what they actually perceive of it. The need for managers to access customers' expectations and their perceptions of the quality provided should be emphasised here. Such an assessment should be constant or, at least, periodic. It should encompass the totality of the service offering, i.e., including every moment of truth, and it should be done for each of the strategic quality dimensions. Gap 13, thus, can be disaggregated into gaps 13.1 to $13 . \mathrm{N}$, according to the $\mathrm{N}$ strategic quality dimensions, just as suggested for Gap 9.

Gap 14 - service quality evaluation. Setting standards is not sufficient to ensure that a quality service is being offered. Accurate measures are essential for monitoring and for effective quality management. Measuring is an objective way to monitor service quality, but personal observation is also important. This should not be confounded with "police action". Several methods can be used to measure quality, however, the best measurements that can be devised «mirror and validate the details of [the organisation's] service strategy» (Zemke \& Schaaf, 1989). Standards are set according to essential strategy elements and measurements must focus on the same fundamental variables (Garvin, 1987).

\section{Importance of SQGs to a strategy implementation process}

From the definitions above, it can be seen that SQGs occur during day-to-day activities and that some may occur during the strategy formulation and implementation process. The SQGs can, thus, be mapped accordingly. Table 2 shows in which of three simple stages of the strategy process is each of the gaps supposed to be more likely to occur. 
Table 2. Relationships between the stages of the strategy process and the SQGs

\begin{tabular}{|c|c|c|c|c|}
\hline \multirow{2}{*}{$\begin{array}{l}\text { Gap } \\
\text { number }\end{array}$} & \multirow{2}{*}{$\begin{array}{c}\text { Gaps that can occur in or arise from the stages of the } \\
\text { process }\end{array}$} & \multicolumn{3}{|c|}{ Stages of the strategy process } \\
\hline & & $\begin{array}{l}\text { Formulation } \\
\text { (Discern) }\end{array}$ & $\begin{array}{l}\text { Implementation } \\
\text { (Develop) }\end{array}$ & $\begin{array}{l}\text { Deliver the } \\
\text { service to delight }\end{array}$ \\
\hline 1 & Management perceptions & ○ & & \\
\hline 2 & Service quality strategy & ○ & & \\
\hline 3 & $\begin{array}{l}\text { Service design and service quality specifications in terms } \\
\text { of customers' expectations }\end{array}$ & 0 & ○ & \\
\hline 4 & Quality supportive financial function & ○ & - & \\
\hline 5 & Internal communications & - & ○ & ? \\
\hline 6 & Integration/ coordination & - & ○ & ? \\
\hline 7 & $\begin{array}{l}\text { Coordination of other people and/or organisations in } \\
\text { the value system }\end{array}$ & ○ & ○ & \\
\hline 8 & $\begin{array}{l}\text { Selection, training, and adequate levels of autonomy, } \\
\text { power and rewards to personnel }\end{array}$ & & 0 & \\
\hline 9 & Service delivery & & & ? \\
\hline 10 & External communications & & & ? \\
\hline 11 & Contact personnel's perceptions of client's expectations & & & - \\
\hline 12 & Contact personnel's perceptions of client's experiences & & & ? \\
\hline 13 & Consumer perceptions & & & ○ \\
\hline 14 & Service quality evaluation & & & 0 \\
\hline
\end{tabular}

Note: This table has provided the criterion used to reorder and renumber the 14 SQGs identified.

Gaps 1 to 7 can occur when discerning customer needs and strategy. Gaps 3 to 8 can occur during development of the organisation capabilities. Finally, Gaps 5 to 14 can occur during day-to-day delivery activities.

If any group of SQGs occurs during strategy formulation or implementation, the process is flawed. In that case, it is probable that the SQGs will become engraved in the organisational processes, routines and culture. All the subsequent organisational activity will be severely affected; the strategy implementation will be considered unsuccessful; and the organisation's competitiveness will be endangered. This reasoning indicates that some SQGs might be conceptualised both as impediments to quality and as impediments to effective strategy implementation. It also suggests that prevention and elimination of SQGs should occur 
previous to, during, and after the strategy process. Thus, an understanding of SQGs becomes necessary before starting any quality strategy formulation and implementation process.

This line of reasoning raises some questions - How are the SQGs related to the process of strategy formulation and implementation? What more specific stages are actually involved in the strategy process? What gaps can occur at those more specifically defined stages? What organisational variables are affected by each gap? What organisational variables can be used to prevent and eliminated the gaps? At what stages? Is the manipulation of organisational variables at one specific stage capable of eliminating any specified gap? Will the gap recur?...

\section{Conclusion}

Drawing on several studies, this paper presents a comprehensive SQG model that amplifies the areas where to look for SQGs. Fourteen SQGs are outlined, some of which can be disaggregated, according to the organisation's strategic quality dimensions. The 14 SQGs encompass relevant aspects in the literature that have not been exploited in previous gap models. For instance, the deliberate definition of an "external coordination" gap or of gaps between internal customers, namely, between members of contact personnel; between contact personnel and support personnel/systems; and between an increased range of organisational functions.

The 14 SQGs are major impediments to service quality, but some can also be seen as impediments to strategy formation and implementation. A link is drawn between the SQGs and the stages of a strategy process, indicating that the model can have strong implications for the process. Thus, successful service quality strategy formation and implementation seems to require an understanding and elimination of SQGs. Hence, because of the impact of SQGs on service delivery, departmental managers must prevent, detect and eliminate them at source. The impact of SQGs on strategy formation and implementation makes it increasingly important for the CEO and staff planners to do the same. 


\section{Acknowledgement}

Carlos Cândido is supported by the Portuguese/EU Programme "Sub-Programa Ciência e

Tecnologia do $2^{\circ}$ Quadro Comunitário de Apoio”.

\section{References}

AdAms, B. \& COlEbOuRne, P. (1989) The Role of Financial Management in Service Organizations. In: JONES, P. (Ed.) Management in Service Industries (London, Pitman Publishing), pp. 223-233.

BATESON, J.E.G. (1995) Managing Services Marketing - Text and Readings (Orlando, The Dryden Press). Brogowicz, A.A., Delene, L.M. \& LYTH, D.M. (1990) A Synthesised Service Quality Model with Managerial Implications, International Journal of Service Industry Management, 1, pp. 27-45.

BROWN, S.W. \& SWARTZ, T.A. (1989) A Gap Analysis of Professional Service Quality, Journal of Marketing, 53, pp. 92-98.

Christopher, M., Payne, A. \& Ballantyne, D. (1993) Relationship Marketing - Bringing Quality, Customer Service and Marketing Together (Oxford, Butterworth-Heinemann).

GARvin, D.A. (1987) Competing on the Eight Dimensions of Quality, Harvard Business Review, 65, Nov.Dec., pp. 101-109.

GRÖNROOS, C. (1990) Service Management and Marketing - Managing the Moments of Truth in Service Competition (Massachusetts, Maxwell MacMillan).

Gummesson, E. (1990) Marketing Organisation in Service Businesses: The Role of the Part-Time Marketer. In: Teare, R., MoutinHo, L. \& Morgan, N. (Ed.) Managing and Marketing Services in the 1990s (London, Cassell), pp. 35-48.

HAYWOOD-FARMER, J. (1988) A conceptual Model of Service Quality, International Journal of Operations and Production Management, 8, pp. 19-29.

IRONS, K. (1994) Managing Service Companies - Strategies for Success (Wokingham, Addison-Wesley Publishing Company).

LAWRENCE, P.R. \& LORSCH, J.W. (1967) Organisation and Environment-Managing Differentiation and Integration (Boston, Harvard University).

LOVELOCK, C.H. (1992) A Basic Toolkit for Service Managers. In: LOVELOCK, C.H. (Ed.) Managing Services - Marketing, Operations, and Human Resources (New Jersey, Prentice-Hall), 17-30. 
MinTZBERG, H. (1979) The Structuring of Organisations (London, Prentice-Hall).

NORMANN, R. (1995) Service Management-Strategy and Leadership in Service Business (Chichester, John Wiley \& Sons).

Normann, R. \& RamireZ, R. (1993) From Value Chain to Value Constellation: Designing Interactive Strategy, Harvard Business Review, 71, July-Aug, pp. 65-77.

Parasuraman, A., ZeITHAmL, V.A. \& Berry, L.L. (1985) A Conceptual Model of Service Quality and Its Implications for Future Research, Journal of Marketing, 49, pp. 41-50.

Parasuraman, A., ZeithamL, V.A. \& BERry, L.L. (1988) SERVQUAL: A Multiple-Item Scale for Measuring Consumer Perceptions of Service Quality, Journal of Retailing, 64, pp. 12-40.

PARASURAmAn, A., ZEITHAML, V.A. \& BERry, L.L. (1991) Refinement and Reassessment of the SERVQUAL Scale, Journal of Retailing, 67, pp. 420-450.

ROSANDER, A.C. (1989) The Quest for Quality in Services (New York, American Society for Quality Control).

ShostacK, G.L. (1984) Designing Services that Deliver, Harvard Business Review, 62, Jan.-Feb., pp. 133139.

Zeithaml, V., Berry, L.L. \& PARAsuraman, A. (1988) Communication and Control Processes in the Delivery of Service Quality, Journal of Marketing, 52, pp. 35-48.

ZEMKE, R. \& SCHAAF, D. (1989) The Service Edge - 101 Companies that Profit from Customer Care New York, NAL Books). 